\title{
Comparison of Lactose Intolerance in Healthy Kuwaiti and Asian Volunteers
}

\author{
Hala Al Sanae ${ }^{a}$ Winston Saldanha $^{a}$ T.N. Sugathan ${ }^{b}$ Abdul Majid Molla ${ }^{b}$ \\ a Department of Pediatrics, Al-Amiri Hospital, and bepartment of Community Medicine, Faculty of Medicine, \\ Kuwait University, Kuwait
}

\author{
Key Words \\ Breath hydrogen - Lactose intolerance - Diarrhea . \\ Flatulence $\cdot$ Abdominal cramps
}

\begin{abstract}
Objective: To study and compare the incidence of lactose intolerance among Kuwaiti and Asian healthy volunteers as measured by breath hydrogen level following challenge with lactose drink. Subjects and Methods: The study involved 70 Kuwaiti and 79 Asian healthy volunteers. The volunteers were physicians, medical students and other hospital workers. The study was carried out prospectively at Amiri Hospital, Kuwait. None of the volunteers was sick or had taken antibiotics or any other drug that could influence breath hydrogen level 2 weeks prior to the study. After an overnight fast $20-\mathrm{ml}$ baseline samples of exhaled air were collected from each volunteer prior to oral administration of $40 \mathrm{~g}$ of lactose drink. Following this, the same amount of exhaled air was collected at 30-min intervals for $2 \mathrm{~h}$. All samples were analyzed for hydrogen level using a Quintron microlyzer. Hydrogen level of 20 ppm more than baseline value was considered positive. Results: The basal breath hydrogen levels were $12.49 \pm 8.4$ and $6.97 \pm 6.9$ for Kuwaitis and
\end{abstract}

Asians, respectively. Thirty-three (47\%) of the 70 Kuwaitis and $46(58 \%)$ of the 79 Asians were positive for the breath hydrogen test. The clinical symptoms of flatulence, abdominal pain, and diarrhea were associated with high levels of breath hydrogen. Conclusion: The findings indicate that the Kuwaiti volunteers had higher breath hydrogen levels than Asians, but the incidence of lactose intolerance was similar in both groups.

Copyright $\odot 2003$ S. Karger AG, Basel

\section{Introduction}

Secondary lactose intolerance in adults is a common condition, particularly among non-Caucasian populations $[1,2]$. In these populations the intestinal brush border enzyme lactase disappears during the late childhood $[3,4]$. It is thought to be due to a genetic trait with agedependent expression [5-7]. The incidence and severity of the symptoms depend on the amount of lactose consumed, the diet with which lactose is drunk [8] and the individual's sensitivity to lactose [9]. Although the incidence of adult lactose intolerance in Asian populations is high [10], its presentation as a clinical problem is relatively uncommon $[11,12]$.

\section{KARGER \\ Fax +4161306 1234 \\ E-Mail karger@karger.ch \\ www.karger.com

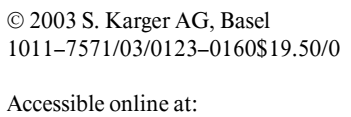

A.M. Molla

Department of Pediatrics, Faculty of Medicine

Kuwait University, PO Box 24923

Safat 13110 (Kuwait)

Tel. +965 5319486, Fax +965 5338940, E-Mail majid@hsc.kuniv.edu.kw 
The type of test used for the diagnosis of lactose intolerance greatly influences the incidence reported. Currently used methods for the diagnosis of lactose intolerance include the breath hydrogen test (BHT), estimation of lactase enzyme from an intestinal biopsy and the lactose tolerance test. In this study, the BHT was used because it is easy to perform and is fairly dependable [13]. However, there still exists controversy in its interpretation, the amount of the substrate used for challenge and the magnitude of the hydrogen level in the breath to be taken as positive result [14]. To our knowledge very limited information is available on lactose intolerance in the Middle Eastern populations [15], but it is fairly well investigated in Asians [10-12]. Since a large population of Asians live in Kuwait and have common cultural and culinary habits, it was decided to study and compare the incidence of lactose intolerance in Kuwaitis and Asians.

\section{Subjects and Methods}

The research project was approved by the Ethics Committee, Amiri Hospital, Kuwait. A total of 149 adult volunteers, 70 Kuwaitis and 79 closely matched Asians, known not to have any gastrointestinal problems were selected for the study. Among the Kuwaitis, male and female were the same, 35 each, but among the Asians 35 were males and 44 females. The mean ages of the Kuwaitis and Asians were $33.4 \pm 2.6$ and $34 \pm 2.84$ years, respectively. The volunteers included physicians, nurses and hospital workers.

One of the investigators carefully explained the procedures to the volunteers in Arabic or English or the volunteer's own language. The volunteers were specifically asked about any illness, use of antibiotics or any other medications. They were also asked about any previous gastrointestinal problems following drinking of milk. Any one with a history of gastrointestinal problems following drinking of milk or on antibiotics within 2 weeks prior to the test was excluded. The BHT was performed after an overnight fast of at least $12 \mathrm{~h}$. Twenty milliliters of end-expiratory air was collected in a plastic syringe connected through a nozzle to the bag into which the subject exhaled. After collection of a baseline sample of exhaled air, the volunteer was given $40 \mathrm{~g}$ of lactose dissolved in $250 \mathrm{ml}$ of water to drink.

Breath sample were collected at 30-min intervals for the next $2 \mathrm{~h}$. The hydrogen concentration in each breath sample was measured using a Quintron microlyzer (Quintron instrument model 12). Peak breath hydrogen was defined as the highest level of breath hydrogen obtained compared to the base level at any time during the subsequent sampling [16]. Hydrogen level of $20 \mathrm{ppm}$ more than baseline value or a difference of $20 \mathrm{ppm}$ between two readings was considered positive [17]. Positive BHT was made on individual readings and not on the average value. Symptoms suggestive of lactose intolerance such as nausea, vomiting, flatulence, abdominal pain and diarrhea were recorded during the next $12 \mathrm{~h}$ by directly asking the subjects. Symptoms were not graded according to severity.
Table 1. Breath hydrogen level (parts per million, ppm, mean \pm SD) in the volunteer groups after challenge with lactose

\begin{tabular}{clcc}
\hline Time, min & $\begin{array}{l}\text { Group 1 } \\
\text { Kuwaiti }(\mathrm{n}=70)\end{array}$ & $\begin{array}{l}\text { Group 2 } \\
\text { Asians }(\mathrm{n}=79)\end{array}$ & $\mathrm{p}$ \\
\hline 0 & $12.49 \pm 8.4$ & $6.97 \pm 6.9$ & $<0.05$ \\
30 & $\mathrm{NA}$ & $8.52 \pm 9$ & $\mathrm{NS}$ \\
60 & $19.41 \pm 23.6$ & $15.67 \pm 1.2$ & $\mathrm{NS}$ \\
90 & $19.20 \pm 19.7$ & $24.65 \pm 29.2$ & $\mathrm{NS}$ \\
120 & $24.66 \pm 23.6$ & $31.42 \pm 31.7$ & $\mathrm{NS}$ \\
\hline
\end{tabular}

$\mathrm{NA}=$ Not available

\section{Statistics}

The SPSS version 9 statistical package was used for data analysis. Descriptive statistics, mean and standard deviations were used to describe the findings. Since the variable under study was found to deviate from Gaussian distribution irrespective of log transformation, a nonparametric method, the Kruskal-Wallis one-way ANOVA, was used to test the differences among three independent groups. The difference in proportions was tested by using Pearson $\chi^{2}$ test. However, Fisher's exact test was used in case of $2 \times 2$ contingency tables with expected counts of less than five.

\section{Results}

Table 1 gives the various levels of breath hydrogen (mean $\pm \mathrm{SD}$ ) over the study period. The basal BHT level of the Kuwaitis was higher than that of the Asian subjects $(\mathrm{p}<0.05)$. Of the 70 Kuwaitis, $33(47 \%)$ and of the 79 Asians, 46 (58\%) had a positive BHT result.

In table 2 is presented the comparison between the levels and the association of BHT levels and clinical symptoms. Of the 70 Kuwaitis, 12 (26.1\%) had nausea and were BHT-positive compared to only 1 with nausea that was BHT-negative $(\mathrm{p}<0.05)$. Among the Asians with nausea, 23 and $16.9 \%$ were BHT-positive and BHT-negative, respectively. Vomiting occurred only in 2 Kuwaitis who were BHT-positive. None of the Kuwaitis with negative BHT had flatulence, but 17 (37.8\%) who were BHTpositive did $(p<0.001)$. Flatulence was not recorded in the Asian group by mistake. One Kuwaiti with abdominal pain had negative BHT, compared to $15(32.6 \%)$ with positive BHT $(\mathrm{p}<0.001)$. On the other hand, $4(15.4 \%)$ of the Asians who complained of abdominal pain were BHTnegative, and $29(54.7 \%)$ were BHT-positive $(\mathrm{p}<0.001)$. Diarrhea was present only in 1 Kuwaiti with negative BHT and $9(19.6 \%)$ with a positive BHT result $(\mathrm{p}<$ 
Table 2. Association of gastrointestinal symptoms with breath hydrogen level (parts per million, ppm)

\begin{tabular}{|c|c|c|c|c|c|c|}
\hline \multirow[t]{2}{*}{ Symptoms } & \multicolumn{2}{|c|}{ Kuwaiti $(\mathrm{n}=70)$} & \multirow[t]{2}{*}{$\mathrm{p}$} & \multicolumn{2}{|c|}{ Asians $(n=79)$} & \multirow{2}{*}{$\mathrm{p}$} \\
\hline & $\begin{array}{l}\text { BHT }<10 \\
(\mathrm{n}=24)\end{array}$ & $\begin{array}{l}\text { BHT >10 } \\
(n=46)\end{array}$ & & $\begin{array}{l}\text { BHT }<10 \\
(\mathrm{n}=26)\end{array}$ & $\begin{array}{l}\text { BHT }>10 \\
(\mathrm{n}=53)\end{array}$ & \\
\hline Nausea & $1(4.2)$ & $12(26.1)$ & $<0.05$ & $6(23.1)$ & $9(16.9)$ & NS \\
\hline Vomiting & $0(0.0)$ & $2(4.4)$ & NS & $0 \quad(0.0)$ & $0 \quad(0.0)$ & NS \\
\hline Flatulence $^{1}$ & $0(0.0)$ & $17(37.8)$ & $<0.001$ & - & - & - \\
\hline Abdominal pain & $1(4.2)$ & $15(32.6)$ & $<0.001$ & $4(15.4)$ & $29(54.7)$ & $<0.001$ \\
\hline Diarrhea & $1(4.2)$ & $9(19.6)$ & $<0.001$ & $9(34.6)$ & $37(69.8)$ & $<0.001$ \\
\hline
\end{tabular}

Percentage is given in parentheses.

1 Flatulence was not recorded among the Asians.
0.001). Nine of the Asians (34.1\%) with a negative BHT result had diarrhea compared to $37(69.8 \%)$ with positive BHT.

\section{Discussion}

Our data indicate that the BHT after lactose challenge can diagnose $50-60 \%$ of adult volunteers of both Arab and Asian origin as lactose malabsorbers. The data also show that the positive BHT result is a good indicator of clinical symptoms. However, some of the subjects, both Arabs and Asians, had symptoms without positive BHT and vice versa: probably because it has been well documented that individuals with lactose maldigestion do not usually develop clinical symptoms, but those with lactose intolerance suffer from clinical symptoms and also become positive for the BHT [18]. Among the clinical symptoms, flatulence, abdominal pain and diarrhea seem to have a stronger association with a positive BHT. It is also known that development of clinical symptoms and their severity depend on the amount of milk consumed and whether or not milk is drunk alone or with food [5].

The incidence of lactose malabsorption that has been demonstrated in this study is similar to that reported previously [19]. The Caucasian population of North Western Europe has a very low incidence; Africans, Asians and Latin-American Indians have a high incidence [20, 21]. However, the incidence among the Arabs has not been studied adequately using satisfactory techniques [22]. It may be necessary to undertake a larger prospective study to explore this problem in the Arab population. Many of the Arab subjects demonstrated high levels of hydrogen in the breath even in the fasting state; the reason for this is unclear. The present study was done with a relatively small number of subjects and a larger study is necessary for evaluating the incidence or prevalence of lactose intolerance in the Arab population.

\section{Conclusion}

Our findings indicate that a substantial percentage of the Kuwaiti population has lactose intolerance and the incidence is similar to that of the Asian population.

\section{Acknowledgments}

Authors gratefully acknowledge the valuable editorial comments of Prof. Jonathan C. Coleman, Professor of Virology, Faculty of Medicine, Kuwait University. We appreciate the statistical assistance of Mrs. Ajitha Suresh, Scientific Assistant, Department of Community Medicine, Kuwait University. Skillful secretarial assistance of Mrs. Bena Pereira is duly acknowledged. 


\section{References}

1 Bayless TM, Rosensweig NS: A racial difference in incidence of lactase deficiency: A survey of milk intolerance and lactase deficiency in healthy adult males. JAMA 1966;197:968972.

2 Sahi T: Genetics and epidemiology of adulttype hypolactasia. Scand J Gastroenterol Suppl 1994;202:7-20.

3 Cautrecasas P, Lockwood DH, Caldwell JR: Lactase deficiency in adults: A common occurrence. Lancet 1965;i:14-18.

4 Newcomer AD, McGill DB, Thomas PJ, Hofman AF: Prospective comparison of indirect methods of detecting lactase deficiency. N Engl J Med 1975;293:1232-1236.

5 Brown KH, Khatun M, Parry L, Ahmed G: Lactose malabsorption in Bangladeshi village children: Relation with age, history of recent diarrhoea, nutritional status, and breast feeding. Am J Clin Nutr 1979;320:1962-1969.

6 Kretchmer N: Lactose and lactase: A historical perspective. Gastroenterology 1971;61:805813.

7 Rosensweig S: Adult lactase deficiency: Genetic control or adaptive response? Gastroenterology 1971;60:464-467.

8 Rosado JL, Gonzalez C, Lopez P, Palma M, Lopez B, Meija L, Baez MC: Lactose maldigestion and milk intolerance: A study in rural and urban Mexico using physiological doses of milk. J Nutr 1994;124:1052-1059.
9 Suarez FL, Savaiano DA: Lactose digestion and intolerance in adult and elderly Asian Americans. Am J Clin Nutr 1994;59:10211024.

10 Flatz G, Henze HJ, Palabiyi Koglu E, Dagalp K, Turkkan T: Distribution of adult lactase phenotypes in Turkey. Geor Med 1986;38: 255-258.

11 Bolin TD, Davis AE, Seah CS, Chua KL, Yong V, Kho KM, Siak CL, Jacob E: Lactose intolerance in Singapore. Gastroenterology 1970;59: 76-84.

12 Bolin TD, Pirola RC, Davis AE: Adaptation of intestinal lactase in the rat. Gastroenterology 1969;57:406-409.

13 Douwes AC, Fernandes J, Degenhart HJ: Improved accuracy of lactose tolerance test in children, using expired $\mathrm{H}_{2}$ measurement. Arch Dis Child 1978;53:939-942.

14 Solomons NW, Garcia-Ibanez R, Viteri FE: Hydrogen breath test of lactose absorption in adults: The application of physiological doses and whole cow's milk sources. Am J Clin Nutr 1980;33:545-554.
15 Barr RG, Watkins JB, Perman JA: Mucosal function and breath hydrogen $\left(\mathrm{H}_{2}\right)$ excretion: Criteria for normal response (abstract). Pediatr Res 1979;13:395.

16 Solomons NW, Barillas C: The cut-off criteria for a positive hydrogen breath test in children: A reappraisal. J Pediatr Gastroenterol Nutr 1986;5:920-925.

17 Veligati LN, Treem WR, Sullivan B, Burke G, Hyams JS: $\Delta 10$ ppm versus 20 ppm: A reappraisal of diagnostic criteria for breath hydrogen testing in children. Am J Gastroenterol 1994;89:758-761.

18 Simoons FJ: The geographic hypothesis and lactose malabsorption: A weighing of the evidence. Am J Dig Dis 1978;23:963-980.

19 Bose DP, Welsh JD: Lactose malabsorption in Oklahoma Indians. Am J Clin Nutr 1973;26: 1320-1322.

20 Ransome-Kuti O, Kretchmer N, Johnson JD Gribble JT: A genetic study of lactose digestion in Nigerian families. Gastroenterology 1975; 68:431-436.

21 Huang SS, Bayless TM: Milk and lactose intolerance in healthy orientals. Science $1968 ; 160$ 83-84.

22 Cook GC, Al-Torki MT: High intestinal lactase concentration in adult Arabs in Saudi Arabia. BMJ 1977;iii:135-136. 